\title{
Motor Origin of Precise Synaptic Inputs onto Forebrain Neurons Driving a Skilled Behavior
}

\author{
(DDaniela Vallentin ${ }^{1,2}$ and Michael A. Long ${ }^{1,2}$ \\ ${ }^{1}$ NYU Neuroscience Institute and Department of Otolaryngology, New York University Langone Medical Center, New York, New York 10016 and ${ }^{2}$ Center for \\ Neural Science, New York University, New York, New York 10003
}

\begin{abstract}
Sensory feedback is crucial for learning and performing many behaviors, but its role in the execution of complex motor sequences is poorly understood. To address this, we consider the forebrain nucleus HVC in the songbird, which contains the premotor circuitry for song production and receives multiple convergent sensory inputs. During singing, projection neurons within HVC exhibit precisely timed synaptic events that may represent the ongoing motor program or song-related sensory feedback. To distinguish between these possibilities, we recorded the membrane potential from identified HVC projection neurons in singing zebra finches. External auditory perturbations during song production did not affect synaptic inputs in these neurons. Furthermore, the systematic removal of three sensory feedback streams (auditory, proprioceptive, and vagal) did not alter the frequency or temporal precision of synaptic activity observed. These findings support a motor origin for song-related synaptic events and suggest an updated circuit model for generating behavioral sequences.
\end{abstract}

Key words: birdsong; intracellular recording; premotor; sequence generation

\section{Introduction}

In the male zebra finch, where sensory feedback is needed to establish (Konishi, 1965; Price, 1979) and actively maintain (Nordeen and Nordeen, 1992; Leonardo and Konishi, 1999; Tumer and Brainard, 2007) normal singing behavior, the forebrain nucleus HVC has been suggested to act as an important site for sensorimotor integration (Margoliash, 1997). HVC plays a central role in song production (Nottebohm et al., 1976; Vu et al., 1994; Long and Fee, 2008), and circuitry within this region enables the generation of precise premotor activity in the neurons projecting to the robust nucleus of the arcopallium (RA) (Hahnloser et al., 2002; Long et al., 2010). Different RA-projecting HVC $\left(\mathrm{HVC}_{(\mathrm{RA})}\right)$ neurons burst at different moments, and together they form a sequence that leads to the patterned activation of song-producing muscles (Fee et al., 2004). HVC receives synaptic inputs from multiple additional sources (Nottebohm et al., 1982; Bauer et al., 2008), which have been shown to carry sensory information (Coleman and Mooney, 2004; Coleman et al., 2007; Ashmore et al., 2008; Bauer et al., 2008; Williams et al., 2012). In certain conditions (sleep and anesthesia), projection neurons

Received Sept. 4, 2014; revised Oct. 21, 2014; accepted Nov. 7, 2014.

Author contributions:D.V. and M.A.L. designed research;D.V. performed research;D.V. and M.A.L. analyzed data; D.V. and M.A.L. wrote the paper.

This research was supported by the National Institutes of Health (R01NS075044), the New York Stem Cell Foundation, and Deutsche Forschungsgemeinschaft (Va 742/1-1/2). We thank György Buzsáki, Georg Kosche, Daniel Okobi, Sam Sober, Lena Veit, and loana Carcea for helpful comments on a previous version of this manuscript. We also acknowledge Wan-Chun Liu (Rockefeller University, New York, NY) for his assistance with the cochlear removal and muting experiments.

The authors declare no competing financial interests.

Correspondence should be addressed to Michael A. Long, NYU Neuroscience Institute and Department of Otolaryngology, New York University Langone Medical Center, New York, NY 10016. E-mail: mlong@med.nyu.edu.

DOI:10.1523/JNEUROSCI.3698-14.2015

Copyright $\odot 2015$ the authors $\quad 0270-6474 / 15 / 350299-09 \$ 15.00 / 0$ within HVC can produce patterned activity elicited by the playback of the bird's own song (BOS) (Lewicki, 1996; Mooney, 2000; Prather et al., 2008; Amador et al., 2013; Hamaguchi et al., 2014), indicating that sensory input can affect the motor system by modulating the behavior of those neurons. The impact of sensory feedback on neurons that drive singing $\left(\mathrm{HVC}_{(\mathrm{RA})}\right.$ neurons) remains unclear, however, and observations in another cell population $\left(\mathrm{HVC}_{(\mathrm{X})}\right.$ neurons) suggest that auditory inputs may be "gated off" during song production (Kozhevnikov and Fee, 2007; Hamaguchi et al., 2014).

To establish the role of sensory feedback in shaping songrelated HVC activity, we used intracellular recordings (Lee et al., 2006; Long et al., 2010; Long and Lee, 2012) to measure the synaptic inputs onto identified HVC projection neurons in the freely moving zebra finch. It had previously been shown that both $\mathrm{HVC}_{(\mathrm{RA})}$ and $\mathrm{HVC}_{(\mathrm{X})}$ neurons receive highly stereotyped inputs during singing (Long et al., 2010; Hamaguchi et al., 2014) that are likely to arise from either sensory or motor sources. In the "sensory model” (Fig. 1B), HVC synaptic inputs could be generated by the aforementioned sensory streams (Fig. 1A), which provide HVC neurons with updated information concerning ongoing performance. In the "motor model" (Fig. 1C), synaptic responses could originate from neurons involved in generating the premotor pattern, including other HVC projection neurons. Here, we test these hypotheses directly in two ways. First, we show that external auditory feedback does not alter the subthreshold activity of HVC projection neurons during singing. Second, we systematically remove a range of sensory feedback streams (auditory, proprioceptive, and vagal) to show that the synaptic profile of both projection types is unaltered despite the fact that song structure may be severely degraded. These data support the motor model to explain the identity of synaptic events during 
singing, which has important implications for our understanding of the connectivity rules underlying this premotor sequence-generating circuit.

\section{Materials and Methods}

All animal maintenance and experimental procedures were performed according to the guidelines established by the Institutional Animal Care and Use Committee at New York University Langone Medical Center. For these experiments, we used adult $(>100 \mathrm{~d}$ post hatch) male zebra finches that were obtained from an outside breeder.

\section{Surgery}

To install the motorized intracellular microdrive, the zebra finch was first anesthetized with isoflurane (1-3\% in oxygen). The base of the microdrive was then affixed to the skull of the bird using dental acrylic. For antidromic identification of projection neurons (Hahnloser et al., 2002), a bipolar stimulating electrode was implanted into RA and/or X and a reliable spike with minimal latency jitter $(<50 \mu$ s) could be evoked with single biphasic ( $200 \mu$ s per phase) current pulses of $<250$ $\mu \mathrm{A}$. After $1-4 \mathrm{~d}$, we prepared a $100-200 \mu \mathrm{m}$ diameter craniotomy above HVC and carefully removed overlying dura. A well was built around the craniotomy using a silicone elastomer (Kwik-Cast; WPI). To protect the brain from desiccation, the well was filled with either PBS or a silicone gel (Dow Corning; 10,000-60,000 cSt) during behavioral observations and with a layer of silicone elastomer overnight.

\section{Electrophysiology}

For intracellular recordings, sharp electrodes with an impedance of 70 $130 \mathrm{~m} \Omega$ were prepared using a modified horizontal micropipette puller (P-97; Sutter Instrument Company) and backfilled with $3 \mathrm{M}$ potassium acetate. Zebra finches were briefly head fixed (without anesthesia) and partially immobilized in a foam restraint to allow for freshly prepared pipettes to be inserted into the microdrive. Once these electrodes were lowered into the brain and began to encounter spiking activity, the bird was released and intracellular recordings were pursued by lowering the pipette through HVC in $\sim 5 \mu \mathrm{m}$ steps. A brief $(10-20 \mathrm{~ms})$ "buzz" pulse was often needed to facilitate the penetration of the membrane. Once a stable recording (spike height: $>40 \mathrm{mV}$, resting membrane potential: $<-50 \mathrm{mV}$, recording duration: $>3 \mathrm{~min}$ ) was achieved, a female bird was presented to elicit directed singing. All membrane potential measurements were digitized at $40 \mathrm{kHz}$ using a National Instruments acquisition board and acquired with custom MATLAB software.

\section{Sound recording}

All sounds (male directed singing and female calls) were recorded using an omnidirectional lavalier microphone (AT 803b; Audio-Technica) that was clipped onto the cage of the male zebra finch. The songs were amplified using a PreSonus Studio Channel amplifier and digitized at 20 $\mathrm{kHz}$ using a National Instruments board.

\section{Manipulations of the sensory system}

All procedures were performed in adult male zebra finches under isoflurane (1-3\% in oxygen) anesthesia. In nearly all cases, sensory manipulations were performed before the installation of the microdrive and in a separate surgery. The details for each procedure are given below:

Deafening. Zebra finches were deafened via bilateral cochlear removal following a previously described protocol (Konishi, 1965). Briefly, after the bird was anesthetized, a small opening was drilled overlying the semicircular canals. The cochlear dome was located, and a bent tungsten wire was used to pull out the cochlea. Complete removal of both cochleae was confirmed by visual inspection of the complete extracted cochlea under a microscope.

Tracheosyringeal nerve cut. Zebra finches were given an incision to expose the trachea. Fat and muscles were pulled to the side and the tracheosyringeal nerve was isolated with fine forceps. A 3-5 mm length of nerve was removed, and the incision into the skin was sutured (Vicario, 1991; Williams and McKibben, 1992).

Muting. Zebra finches were muted using a procedure described previously (Amador and Margoliash, 2013). Briefly, a small incision was made to separate the adipose tissue from the breast muscles. Vannas spring scissors were used to pierce the membrane of the interclavicular air sac so that a $2-3 \mathrm{~cm}$ long $0.04 / 0.05$ " (ID/OD) silicone tube (Braintree Scientific) could be inserted and secured to the membrane using a tissue adhesive (Vetbond; $3 \mathrm{M}$ ). The tube was then sutured to the breast muscle and surrounded with a silicone elastomer (Kwik-Cast; WPI). When the bird was not being recorded, the tube was closed on one end with a 00-90 $\times 1 / 2$ " nylon pan head screw. Once the bird had recovered from surgery and resumed singing, the tube was opened and the recording session began. In one case, an $\mathrm{HVC}_{(\mathrm{RA})}$ neuron was held before and after the opening of the tube (Fig. $6 F$ ). In that experiment, it was possible to secure the bird and to manually close the tube while maintaining the recording of the cell.

\section{Data analysis}

All data are presented as mean $\pm \mathrm{SD}$. Where not otherwise stated, statistical differences between conditions were tested using Wilcoxon ranksum test for unpaired data or Wilcoxon signed-rank test for paired data.

Spike analysis. The song and the accompanying spiking activity were aligned by detecting the onset and the offset of each motif and warping the electrophysiological trace linearly across trials. A burst was defined as an accumulation of spikes whose interspike interval is $<10 \mathrm{~ms}$. The center of the burst $(c b)$ was defined as the midpoint between the first and last spike in the burst relative to the start of the motif. The root mean square (rms) jitter of the burst was defined as follows:

$$
\text { rms jitter }=\sqrt{\frac{\sum(c b-\text { mean }(\mathrm{cb}))^{2}}{\text { number of motifs }}}
$$

PSP analysis. Data were downsampled to $10 \mathrm{kHz}$ and smoothed with a moving average filter with a span size of five samples. The mean value was then subtracted from each trace, and spikes were removed using a linear interpolation method. Putative EPSPs whose amplitude exceeded $2 \mathrm{mV}$ were detected with a customized local minima and maxima detection algorithm (MATLAB) and the timing, amplitude, and frequency of these events were determined. Due to the high impedance of the "sharp" microelectrode, we were unable to inject sufficient depolarizing current to expose inhibitory synaptic potentials that are often shunting in nature (exhibiting a reversal potential near the resting membrane potential). As a result, we did not attempt to categorize or quantify presumed inhibitory events.

Subthreshold cross-correlation. To analyze the similarity of recorded traces, we performed a cross-correlation measure on subthreshold membrane potential activity. From the song-aligned membrane potential, the mean value was subtracted. A thresholding algorithm detected and removed the spikes ( $\pm 3 \mathrm{~ms}$ ) and the subsequent gap was linearly interpolated. The resulting trace was called the "subthreshold membrane 
A

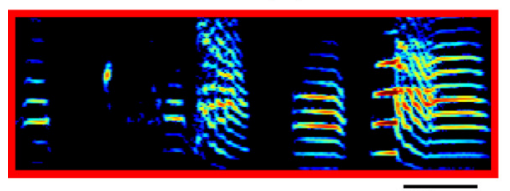

B
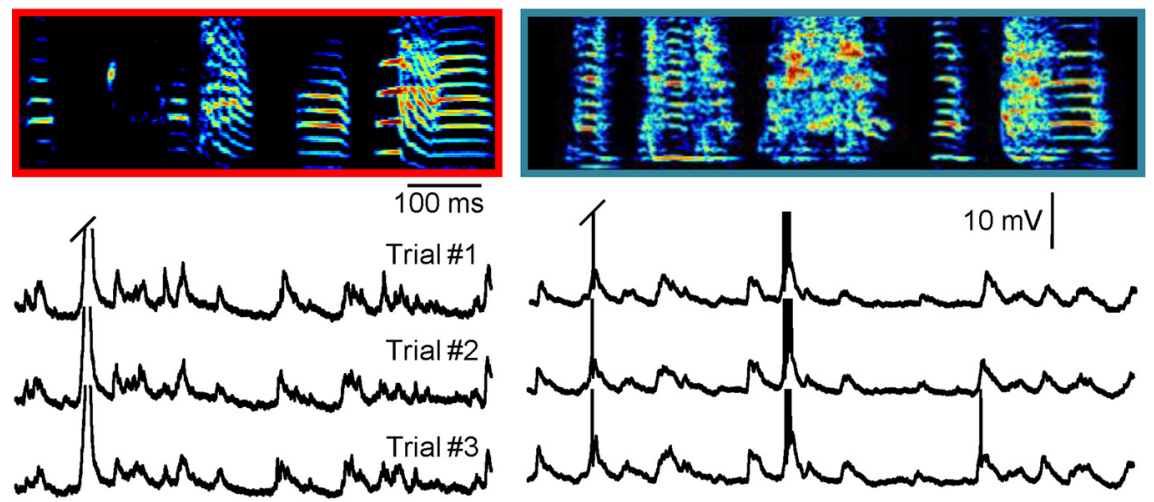

C

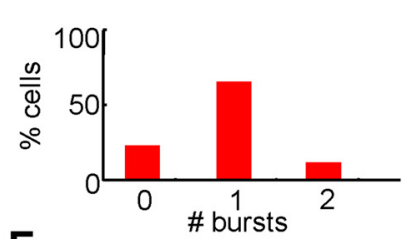

E

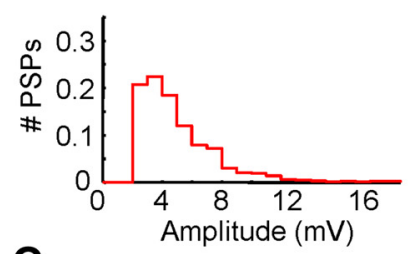

G

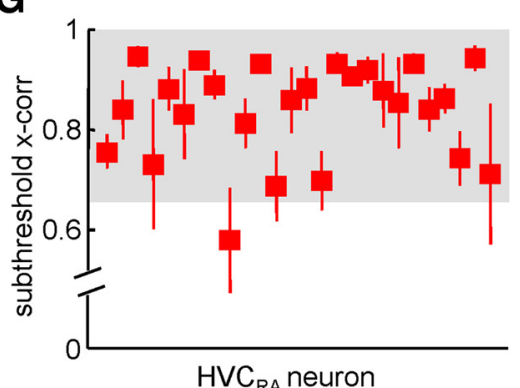

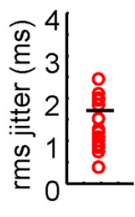

D
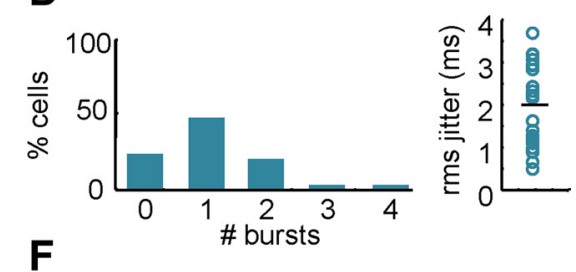

$\mathbf{F}$
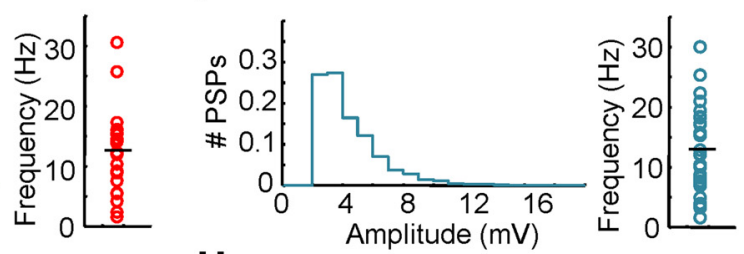

H

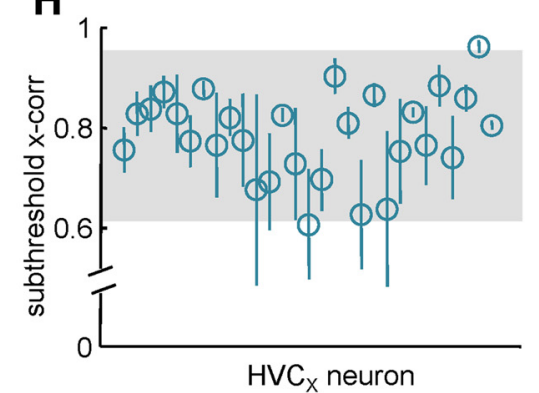

Figure 2. Song-related intracellular activity of HVC projection neurons. $A, B$, Membrane potential of an $\mathrm{HVC}_{(\mathrm{RA})}$ neuron $(\boldsymbol{A})$ and an $\mathrm{HVC}_{(\mathrm{X})}$ neuron $(\boldsymbol{B})$ during the production of three repetitions of a song motif (sonogram frequency: $0.5-7.5 \mathrm{kHz}$ ). $\boldsymbol{C}, \boldsymbol{D}$, Number of bursts per motif (left) and the jitter of burst events in relation to the song (right) as observed in $\mathrm{HVC}_{(\mathrm{RA})}$ neurons $(C)$ and $\mathrm{HVC} \mathrm{C}_{(\mathrm{X})}$ neurons $(\boldsymbol{D}) . \boldsymbol{E}, \boldsymbol{F}$, Normalized distribution of PSP amplitudes and the mean frequency of these events in $\mathrm{HVC}_{(\mathrm{RA})}$ neurons $(\boldsymbol{E})$ and $\operatorname{HVC}_{(\mathrm{X})}$ neurons $(\boldsymbol{F}) . \boldsymbol{G}, \boldsymbol{H}$, Subthreshold cross-correlation coefficient extracted from $\mathrm{HVC}_{(\mathrm{RA})}$ neuron $(\boldsymbol{G})$ and $\mathrm{HVC}_{(\mathrm{X})}$ neuron $(\boldsymbol{H})$ activity during singing (shaded region $=95 \%$ confidence interval).

potential trace." The subthreshold membrane potential traces were cross-correlated. The $95 \%$ confidence interval (mean value $\pm 1.96 \times \mathrm{SD}$ ) was extracted from the cross-correlation values of the control (normal singing) condition.

Song similarity. For quantification of song degradation, spectral features of the song were measured to calculate the degree of similarity to the presurgical song (Song Analysis Pro 2011, SAP 2011; Tchernichovski et al., 2000). Briefly, we obtained two different measures of song similarity: (1) "\% similarity" measures the percentage of a song that is considered to be similar (based on $50 \mathrm{~ms}$ intervals) to the song it is compared with and (2) "accuracy" measures the local similarity of sections on a $1 \mathrm{~ms}$ timescale. To establish a conservative measure of song similarity we calculated "Global Similarity" $=\%$ similarity $\times$ accuracy. SAP 2011 considers acoustic features such as pitch, goodness of pitch, frequency and amplitude modulation, and Wiener entropy between song motifs to provide a statistical estimate of overall similarity. We used the SAP 2011 default settings that are optimized for zebra finch song: $p=0.05$, interval $=70$ $\mathrm{ms}$; minimum duration $=15 \mathrm{~ms}$ applied on the entire motif. For scoring similarity, we used the asymmetric and time course settings. For each bird, we compared 3-10 motifs.

Quantification of the remaining sound after muting. A zebra finch song motif is typically composed of a repeated sequence of syllables that are separated by silent gaps. We focused our analysis exclusively on the syllables produced by removing the intersyllable intervals. To accomplish this, we extracted the duration (relative to an amplitude threshold) of each syllable before the implantation of the muting tube. Following muting, song motifs were analyzed with the identical presurgical amplitude threshold. The "\% sound" was defined as the percentage of syllable-related sound that remained after muting with respect to the presurgical syllable duration within a motif.

Subthreshold membrane potential differences during female calls. The time of a female call during a motif was manually extracted. We restricted our analysis to a time window that encompasses the duration of the call that occurred during the motif but was delayed by $20 \mathrm{~ms}$ to account for the time needed for auditory responses to impact HVC (Margoliash, 1983). The difference of the subthreshold membrane potential trace during the female call and the same epoch of an averaged subthreshold membrane potential (from multiple motifs lacking a female call) was taken. An identical analysis for a portion of the motif lacking a female call was applied to allow for a statistical comparison.

\section{Results}

Intracellular activity in HVC projection neurons during singing

We used a motorized intracellular microdrive (Long et al., 2010) to record song-related activity from antidromically identified HVC projection neurons in 14 adult male zebra finches. Consistent with previous extracellular recordings (Hahnloser et al., 2002; Kozhevnikov and Fee, 2007; Amador et al., 2013; Woolley et al., 2014), both $\mathrm{HVC}_{(\mathrm{RA})}$ neurons ( $n=$ $26)$ and $\mathrm{HVC}_{(\mathrm{X})}$ neurons $(n=29)$ often exhibited high-frequency burst firing during singing (Fig. 2A-D). $\mathrm{HVC}_{(\mathrm{RA})}$ neurons generated an average of $0.8 \pm 0.6$ bursts per motif with $3.9 \pm 1.9$ spikes per burst. $\mathrm{HVC}_{(\mathrm{X})}$ neurons were typically more active, with $1.1 \pm 1.0$ bursts per motif with $3.9 \pm 2.1$ spikes per burst. The bursting events of both $\mathrm{HVC}_{(\mathrm{RA})}$ and $\mathrm{HVC}_{(\mathrm{X})}$ neurons were highly temporally precise, with an average jitter (see Materials and Methods for details) of $1.7 \pm 1.2$ and $2.0 \pm 1.0 \mathrm{~ms}$, respectively. Both cell classes also exhibited large amplitude $(>2$ $\mathrm{mV}$ ) depolarizing postsynaptic potentials during singing (Fig. $\left.2 \mathrm{~A}, \mathrm{~B} ; \mathrm{HVC}_{(\mathrm{RA})}=5.12 \pm 3.07 \mathrm{mV}, \mathrm{HVC}_{(\mathrm{X})}=4.36 \pm 2.01 \mathrm{mV}\right)$, occurring with an average frequency of $12.9 \pm 6.5\left(\mathrm{HVC}_{(\mathrm{RA})}\right)$ and $13.5 \pm 7.1 \mathrm{~Hz}\left(\mathrm{HVC}_{(\mathrm{X})}\right.$; Fig. 2 E,F $)$. We next quantified the extent to which synaptic activity was precisely timed across motifs. Rather than restrict our analysis to large, identifiable synaptic events, we used a cross-correlation approach that simply measured the regularity of the entire subthreshold profile. Using this 
methodology, we found that the synaptic activity was highly stereotyped across motif renditions (Fig. $2 A, B$ ) with subthreshold cross-correlation values of $0.83 \pm 0.10$ $\left(\mathrm{HVC}_{(\mathrm{RA})}\right)$ and $0.78 \pm 0.09\left(\mathrm{HVC}_{(\mathrm{X})}\right.$; Fig. $2 G, H)$. The stereotypy observed in these electrophysiological recordings was mirrored in the behavioral performance; singing was highly regular across renditions, with a Global Similarity of $76.1 \pm$ $6.7 \%$ (see Materials and Methods for details).

Acoustic perturbations have no impact on HVC projection cell activity

Our primary goal was to understand the impact of sensory inputs on HVC activity in the zebra finch during song performance. It had previously been shown that an external auditory stimulus (bird's own syllable or a noise burst) generated through a nearby loudspeaker was insufficient to drive spiking (Kozhevnikov and Fee, 2007; Hamaguchi et al., 2014) or subthreshold (Hamaguchi et al., 2014) activity in $\mathrm{HVC}_{(\mathrm{X})}$ neurons during singing. Because the importance of $\mathrm{HVC}_{(\mathrm{X})}$ neurons for singing behavior may be limited in the adult zebra finch (Scharff et al., 2000), we wanted to extend this observation to understand the impact of an external auditory stimulus on the $\mathrm{HVC}_{(\mathrm{RA})}$ population, which has a central role in driving downstream song production circuits. For these experiments, we chose to examine the cellular and behavioral consequences of a female call (Fig. $3 A, B$ ), because this stimulus has been shown to have the capacity to perturb ongoing singing behavior (Williams, 2004). Across four birds whose activity was further examined for these experiments, 98 of 290 $(33.8 \%)$ directed song motifs were accompanied by at least one female call. In our experiments, we did not observe a significant change in the duration of the motif or syllable order as the result of the female call (Fig. $3 A, B$ ). We next directly investigated the membrane potential of HVC projection neurons (Fig. $3 B, D$ ). The subthreshold activity of both $\mathrm{HVC}_{(\mathrm{RA})}$ (Fig. $3 C ; n=6$ neurons) and $\mathrm{HVC}_{(\mathrm{X})}$ neurons (Fig. $3 B, D ; n=6$ neurons) during segments in which a female call appeared was not significantly different from the average membrane potential values recorded across all motifs lacking an overlying female call.

Song-related HVC activity in the absence of auditory feedback

Given the fact that auditory-evoked responses in HVC are highly BOS selective in the anesthetized bird (Lewicki, 1996; Mooney, 2000), the possibility exists that the female call we attempted to

B

C
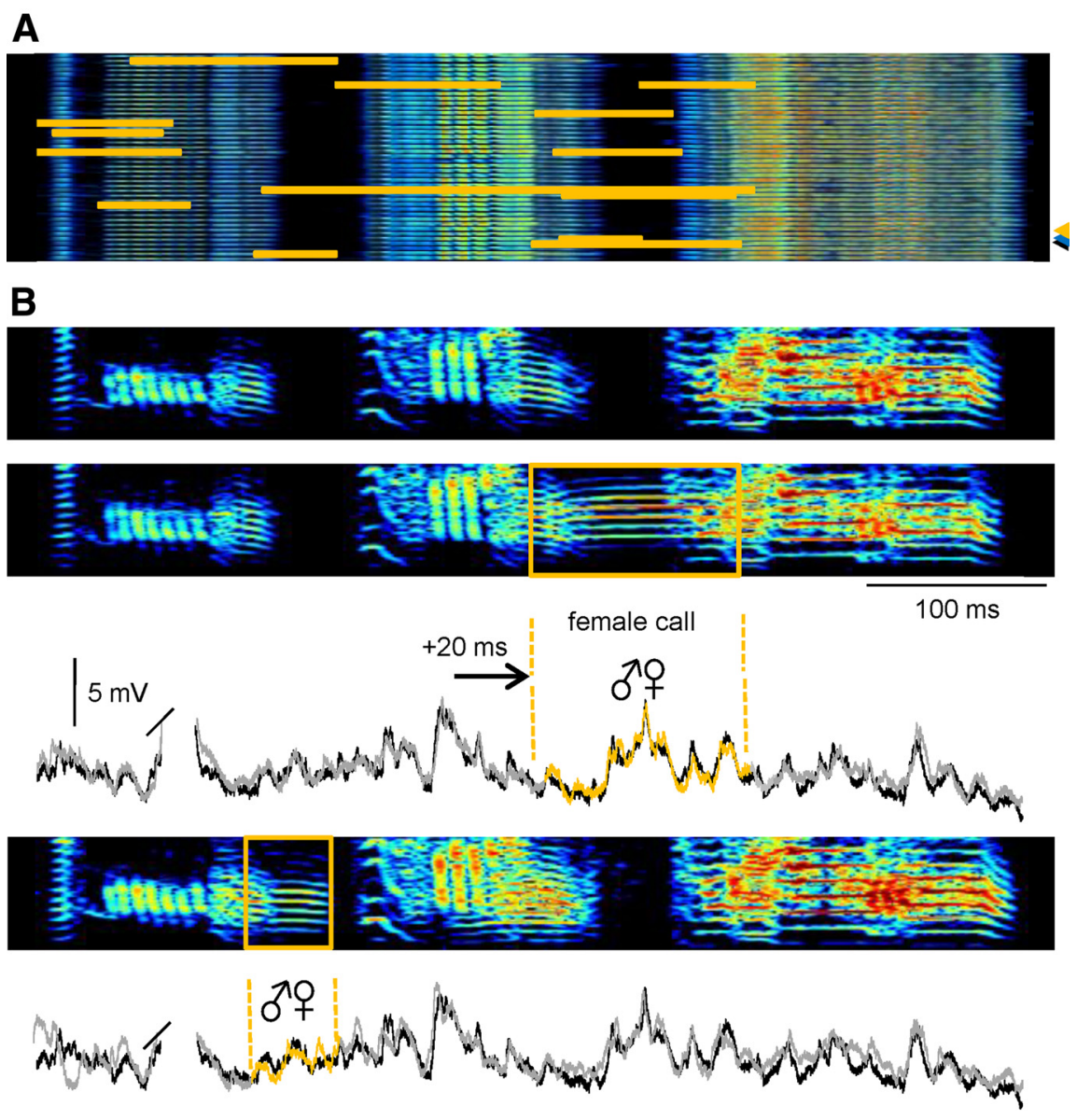
$\begin{array}{lll}H V C_{(R A)} & \text { D } & H V C_{(X)}\end{array}$
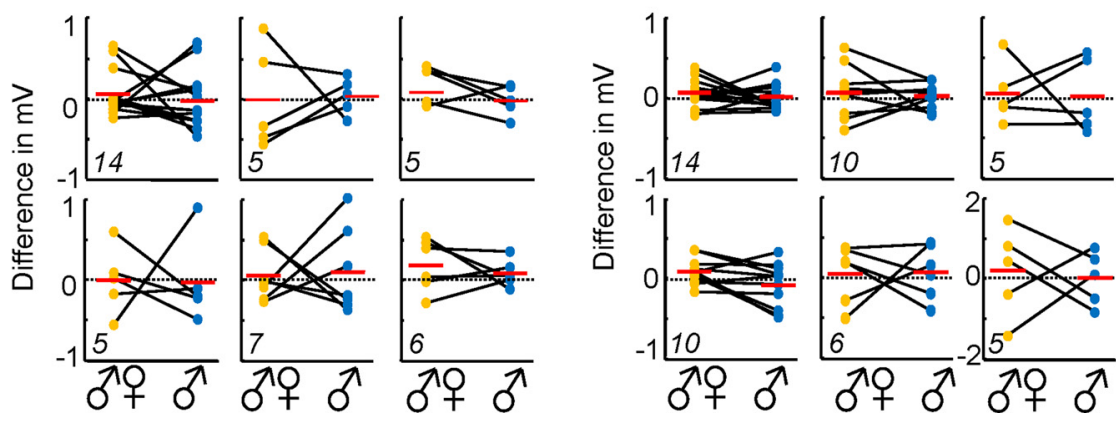

Figure 3. Impact of an auditory perturbation during singing. $\boldsymbol{A}$, The timing of female calls (indicated in orange) is shown across 42 motif sonograms from one bird. $\boldsymbol{B}$, Sonograms of a control song motif (indicated in $\boldsymbol{A}$ by a blue arrowhead) and two motifs that include a female call (indicated in $\boldsymbol{A}$ by yellow and black arrowheads, respectively). Two overlays of intracellular traces of a single $H V C_{(X)}$ neuron recorded during the motifs shown above (black line, control motif; gray/orange line, motif with female call). $C, D$, The change in song-related membrane potential in the presence of a female call vocalization relative to control conditions for a population of six $\mathrm{HVC}_{(\mathrm{RA})}(\boldsymbol{C})$ and six $\mathrm{HVC}_{(\mathrm{X})}$ cells $(\boldsymbol{D})$. Different parts represent single neurons. The total number of female calls analyzed per cell is indicated in the lower left corner of each part. Orange dots represent the difference between a single, subthreshold song-related trace recorded during a female call and the same epoch of an average subthreshold membrane potential from multiple motifs lacking a female call. An identical analysis for a portion of the motif without a female call is provided (blue dots) to allow for a statistical comparison. The first part in $\boldsymbol{D}$ displays the result for the example highlighted in $\boldsymbol{B}$.

use to perturb HVC dynamics during singing may have a minimal impact. To investigate the importance of song-related auditory feedback on the activity of HVC neurons, we removed the cochleae bilaterally in nine adult zebra finches (Konishi, 1965). Upon deafening, the song of each bird was often degraded compared with the presurgical condition (Fig. 4A,B). Consistent with previous results (Nordeen and Nordeen, 1992, 2010; Lombardino and Nottebohm, 2000), the time after deafening was 
A
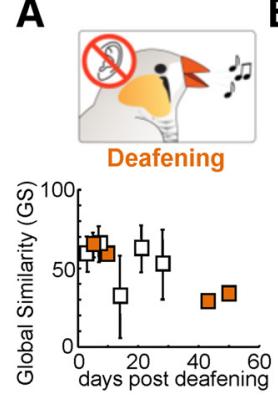

B Presurgical
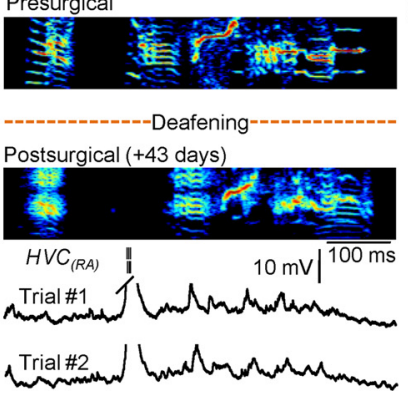
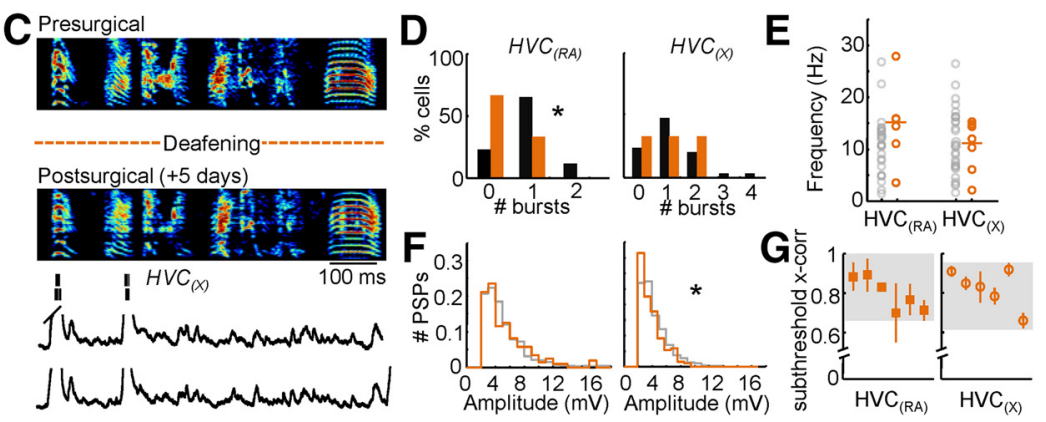

Figure 4. Impact of deafening on singing behavior and HVC projection neuron activity. $\boldsymbol{A}$, Global similarity of singing behavior (presurgical vs deafened motifs) of nine birds recorded at different time points after deafening. Filled symbols represent birds used for electrophysiological experiments. $\boldsymbol{B}$, Example of a bird's presurgical song (top) and a highly deteriorated song produced $43 \mathrm{~d}$ after deafening (middle). The dotted line symbolizes the timing of the surgical procedure. Intracellular recordings during singing are provided for an $\mathrm{HVC}_{(\mathrm{RA})}$ neuron. The membrane potential trace labeled Trial \#1 corresponds to the postsurgical motif displayed directly above (43 d after deafening). Trial \#2 shows an additional rendition of a motif for that cell. Spikes are clipped and spike times are indicated with tick marks. C, Example of a different bird's presurgical song (top) and a song produced $5 \mathrm{~d}$ after deafening (middle). Two intracellular recordings during singing of the postsurgical song

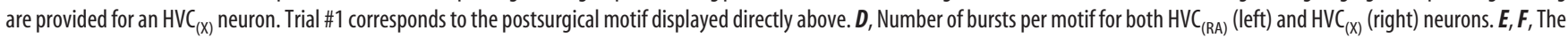
mean frequency $(\boldsymbol{E})$ and amplitude $(\boldsymbol{F})$ distribution of identified excitatory synaptic inputs for $\mathrm{HVC}_{(\mathrm{RA})}$ and $\mathrm{HVC}_{(\mathrm{X})}$ neurons after deafening $\left({ }^{*} p<0.05\right.$ difference from control). For comparison, the data reported in the control condition are displayed in gray. G, Subthreshold correlation coefficients were calculated for all cells recorded after deafening (shaded region $=95 \%$ confidence interval calculated from control conditions).

positively correlated with the extent of song degradation (Fig. $4 A-C)$. Although normal auditory feedback is necessary to maintain the learned song (Nordeen and Nordeen, 1992; Leonardo and Konishi, 1999; Lombardino and Nottebohm, 2000; Tumer and Brainard, 2007), the performance of the deafened birds was highly stereotyped over the span of $1 \mathrm{~d}$ (Global Similarity = $72.0 \pm 9.2 \%$ for postdeafening comparison, Global Similarity $=$ $76.9 \pm 3.2 \%$ for presurgical comparison), supporting the idea that the underlying motor commands for song production may remain intact (McCasland and Konishi, 1981; Brainard and Doupe, 2000). We recorded neuronal activity from four adult zebra finches after deafening. Despite a small but significant change in the number of bursts observed per motif in $\mathrm{HVC}_{(\mathrm{RA})}$ neurons $(p<0.05$; Fig. $4 D)$, the number of spikes per burst during singing in $\mathrm{HVC}_{(\mathrm{RA})}$ neurons $(3.8 \pm 1.1)$ and $\mathrm{HVC}_{(\mathrm{X})}$ neurons $(4.5 \pm 0.9)$ was not significantly different from normal. Bursts remained precisely timed, with temporal jitters $\left(\mathrm{HVC}_{(\mathrm{RA})}=\right.$ $1.4 \pm 1.7 \mathrm{~ms}, \mathrm{HVC}_{(\mathrm{X})}=2.3 \pm 1.8 \mathrm{~ms}$ ) that were not significantly different from control values. In addition, deafening did not affect the frequency of song-related depolarizing synaptic potentials in both cell types (Fig. $4 E$; $\mathrm{HVC}_{(\mathrm{RA})}=14.47 \pm 7.94 \mathrm{~Hz}, \mathrm{HVC}_{(\mathrm{X})}=$ $11.02 \pm 4.97 \mathrm{~Hz})$, despite a small decrease in the amplitude of these events in $\mathrm{HVC}_{(\mathrm{X})}$ neurons (Fig. $4 F$; $\mathrm{HVC}_{(\mathrm{RA})}=5.35 \pm 3.11 \mathrm{mV}$, $\left.\mathrm{HVC}_{(\mathrm{X})}=4.00 \pm 1.71 \mathrm{mV} ; p<0.05\right)$. Synaptic activity was still precisely timed in the absence of auditory input, leading to high intertrial subthreshold cross-correlation values for both cell types (Fig. $4 G ; \mathrm{HVC}_{(\mathrm{RA})}=0.80 \pm 0.08, \mathrm{HVC}_{(\mathrm{X})}=0.82 \pm 0.10$ ) that were not significantly different from values measured in birds with normal hearing. These data show that the postsynaptic events observed in HVC projection neurons during singing are not driven by auditory feedback.

\section{Song-related HVC activity in the absence of syringeal proprioceptive feedback}

Because deafened birds are still capable of producing a stereotyped song within the span of $1 \mathrm{~d}$, it is conceivable that the precisely timed synaptic activity in their HVC projection neurons may originate from other afferent sources during singing. Proprioceptive afferents from the syrinx provide an important source of sensory feedback (Bottjer and Arnold, 1984; Vicario, 1991; Williams and McKibben, 1992). To estimate the role of these inputs on song-related HVC activity, we severed the tracheosyringeal nerve bilaterally, which resulted in syringeal deafferentation. An additional consequence of this manipulation is that the efferent pathway from the song-control nuclei to the syrinx was also disrupted. Because descending motor inputs to respiratory areas are preserved, the syllables largely retain their order and duration (Fig. 5A, B; postsurgical-postsurgical Global Similarity $=78.8 \pm$ $8.6 \%$ ) despite a significant loss of fine structure in the song (Fig. $5 A, B)$. Indeed, the Global Similarity between normal song and song produced after the vocal nerve lesion dropped to $21.2 \pm$ $4.5 \%$, and the conversion of much of the syllable structure to harmonic stacks led to a significant increase in goodness of pitch and a decrease in FM modulation compared with controls (Fig. $5 A$ ). As a consequence, severing the tracheosyringeal nerve resulted in a marked distortion of singing behavior and auditory feedback as well as a blockade of syringeal feedback. Despite this, there were no significant differences in the number of spikes per burst $\left(\mathrm{HVC}_{(\mathrm{RA})}=4.0 \pm 1.9, \mathrm{HVC}_{(\mathrm{X})}=3.9 \pm 2.1\right)$ or the temporal precision of bursts ( $\mathrm{rms}$ jitter: $\mathrm{HVC}_{(\mathrm{RA})}=1.6 \pm 0.8 \mathrm{~ms}$, $\left.\mathrm{HVC}_{(\mathrm{X})}=2.2 \pm 1.4 \mathrm{~ms}\right)$. Similarly, there was no change in frequency $\left(\mathrm{HVC}_{(\mathrm{RA})}=13.80 \pm 5.47 \mathrm{~Hz}, \mathrm{HVC}_{(\mathrm{X})}=10.18 \pm 4.67\right.$ $\mathrm{Hz})$, amplitude $\left(\mathrm{HVC}_{(\mathrm{RA})}=4.68 \pm 2.16 \mathrm{mV}, \mathrm{HVC}_{(\mathrm{X})}=4.57 \pm\right.$ $2.12 \mathrm{mV})$, or across-trial reliability $\left(\mathrm{HVC}_{(\mathrm{RA})}=0.82 \pm 0.07\right.$, $\left.\mathrm{HVC}_{(\mathrm{X})}=0.82 \pm 0.05\right)$ of subthreshold activity compared with control conditions (Fig. 5B-E), lending further support to the notion that synaptic events measured during singing are unlikely to result from reafferent sensory streams.

\section{Song-related HVC activity following a reversible disruption of sensory feedback}

Previous work has implied an important role for sensory feedback from vagal afferents innervating the air sac (Ashmore et al., 2008; Méndez et al., 2010). To test the possibility that these signals are influencing the ongoing motor pattern, we implanted small muting tubes in the interclavicular air sac of seven birds. The tube was capable of significantly decreasing air sac pressure leading to the severe disruption of singing behavior (Fig. $6 A, B, F)$. The tube remained closed outside of observation periods, which allowed the bird to produce a vocalization that more closely resembled the presurgical song (Fig. $6 B, F$ ) and limited the possibility of long-term adaptive changes that may occur following a more permanent manipulation. As with the tracheosyringeal nerve cut, the muting manipulation resulted in the 
perturbation of auditory feedback as well as partially eliminated sound production. The four muted zebra finches used for electrophysiological recordings still attempted to produce intact motifs but $<38 \%$ of the total sound remained when the tube was open (Fig. $6 A, B, F$ ). The portions of the motif that remained following the insertion of the muting tube were still stereotyped $(\%$ Global Similarity = $56.8 \pm 13.9 \%)$ but no longer resembled the normal motifs ( $\%$ Global Similarity $=$ $21.0 \pm 20.3 \%)$. Following muting, there was no change in the number of bursts per motif (Fig. 6C), spikes per burst (HV$\left.\mathrm{C}_{(\mathrm{RA})}=3.9 \pm 1.3, \mathrm{HVC}_{(\mathrm{X})}=5.1 \pm 2.5\right)$, or burst regularity ( $\mathrm{rms}$ jitter: $\mathrm{HVC}_{(\mathrm{RA})}=$ $\left.0.9 \pm 0.3 \mathrm{~ms}, \mathrm{HVC}_{(\mathrm{X})}=1.3 \pm 0.9 \mathrm{~ms}\right)$. The frequency of postsynaptic potentials was unaffected $\left(\mathrm{HVC}_{(\mathrm{RA})}=13.01 \pm 1.95\right.$ $\left.\mathrm{Hz}, \mathrm{HVC}_{(\mathrm{X})}=12.68 \pm 5.74 \mathrm{~Hz}\right)$, despite a small increase in the amplitude of synaptic events observed for both cell types $\left(\mathrm{HVC}_{(\mathrm{RA})}=6.37 \pm 3.34 \mathrm{mV}, \mathrm{HVC}_{(\mathrm{X})}=\right.$ $5.71 \pm 3.13 \mathrm{mV} ; p<0.05$; Fig. $6 E$ ). As before, synaptic activity remained highly correlated across trials (Fig. $6 \mathrm{E}$; $\mathrm{HVC}_{(\mathrm{RA})}$ $\left.=0.80 \pm 0.03, \mathrm{HVC}_{(\mathrm{X})}=0.78 \pm 0.04\right)$. In one case, we were able to maintain a recording of an $\mathrm{HVC}_{(\mathrm{RA})}$ neuron during both partially muted ("tube open") and control ("tube closed") conditions (Fig. $6 F$ ). In this experiment, we could perform a "within neuron" observation to directly examine the contribution of sensory feedback to the exact timing of synaptic events during song production. The song-related membrane potential of that neuron in the tube open condition was highly correlated with the tube closed condition $(0.75 \pm$ 0.08 , within the $95 \%$ confidence interval of control data), directly demonstrating that sensory input was insufficient to explain the appearance of specific synaptic events. In total, we have either eliminated or significantly altered multiple sensory feedback streams with no change in the number of excitatory events measured in HVC projection neurons or in their relative timing as measured through our subthreshold crosscorrelation analysis.

\section{Discussion}

Sensory feedback does not explain song-related HVC synaptic activity

During singing, projection neurons within HVC exhibit a highly stereotyped pattern of synaptic potentials (Long et al., 2010; Hamaguchi et al., 2014) that could either originate from the neurons involved in producing the song or a variety of sensory streams providing afferent feedback. In our experiments, we used a number of manipulations to rule out a sensory source for these events, and we used intracellular recordings during singing, which not only enabled us to detect the spiking output of HVC projection neurons but also allowed for a rigorous dissection of their synaptic inputs. Previous observations showed that acoustic perturbations did not alter song-related spiking (Kozhevnikov and Fee, 2007) and excitatory synaptic (Hamaguchi et al., 2014) activity observed in $\mathrm{HVC}_{(\mathrm{X})}$ projection neurons. Here we extended this observation to include $\mathrm{HVC}_{(\mathrm{RA})}$ neurons because of their central role in song production in the adult zebra finch. Additionally, our recordings were exclusively performed in the context of directed singing, while the previous recordings were obtained during undirected singing (Hamaguchi et al., 2014). Both studies lead to the conclusion that a variety of external sound stimuli are incapable of altering ongoing song-related HVC synaptic patterns, independent of social context. Following three separate methods of sensory deprivation (deafening, vocal nerve cut, and muting), we observed the same frequency of synaptic potentials in both HVC projection cell types as seen in control conditions. These results indicate that the depolarizing synaptic inputs measured during singing are not mediated by sensory feedback. Importantly, the song-related synaptic inputs measured across motifs were still precisely timed in the absence of individual sensory streams, demonstrating that the timing of the synaptic inputs is controlled by motor sources. Despite the over- 
A
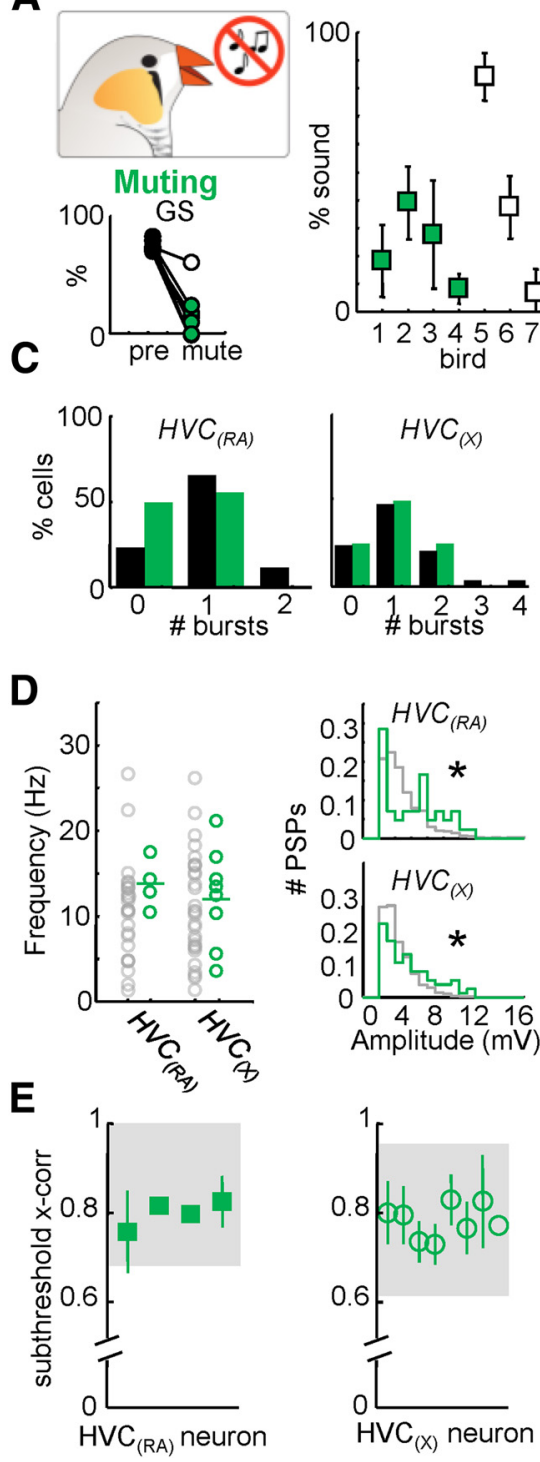

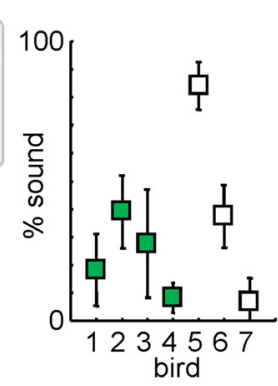

B
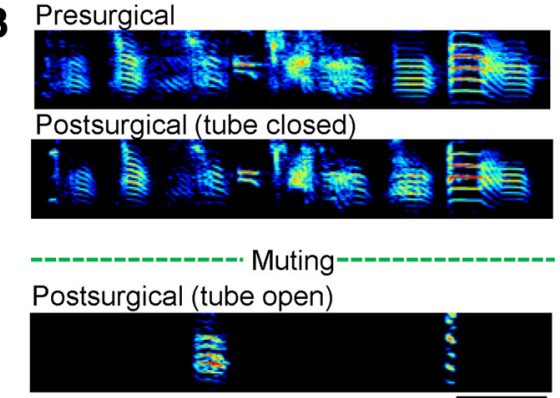

Postsurgical (tube open)
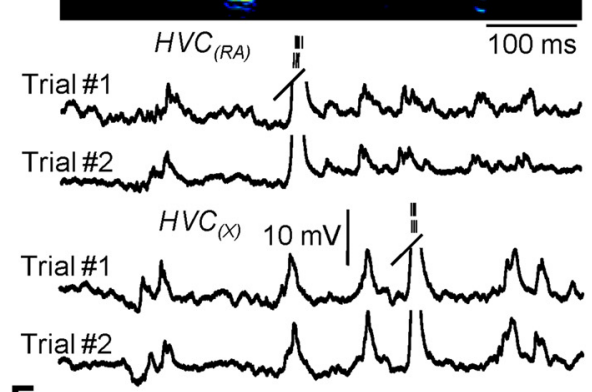

$\mathbf{F}$

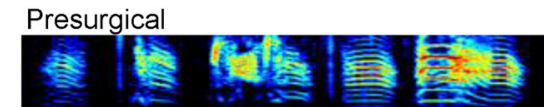

Postsurgical (tube closed)
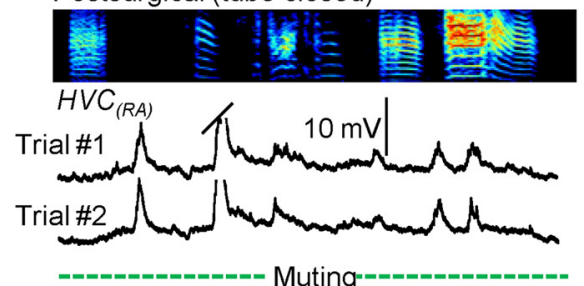

Postsurgical (tube open)

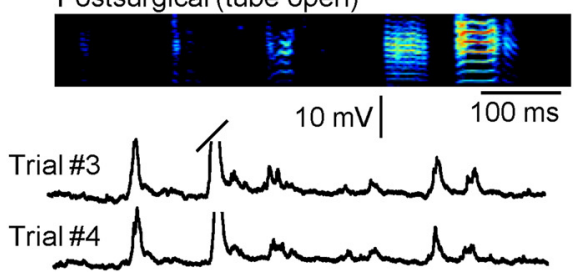

Figure 6. Behavioral and electrophysiological effects of reversible muting. $A$, Percentage of presurgical song remaining after muting ( $n=7$ birds; right). Global similarity (GS) during normal and postsurgical (tube open) song production. $\boldsymbol{B}$, Three motif examples from one bird highlighting the reversible muting approach: Presurgical (top); Postsurgical, tube closed (96\% song remaining, middle); and Postsurgical, tube open (18\% song remaining, bottom). Below the sonograms, example intracellular traces of an $\mathrm{HVC}_{(\mathrm{RA})}$ and an $\mathrm{HVC}_{(\mathrm{X})}$ neuron recorded during two repetitions of the postsurgical (tube open) motif are displayed. Trial $\# 1$ of the $\mathrm{HVC}_{(\mathrm{RA})}$ neuron corresponds to the postsurgical (tube open) motif shown above. $C$, Number of bursts per motif for both $\mathrm{HVC}_{(\mathrm{RA})}$ and $\mathrm{HVC}(\mathrm{X})$ neurons. D, The mean frequency and amplitude distribution of identified excitatory synaptic inputs for $\mathrm{HVC}_{(\mathrm{RA})}$ and $H_{V} C_{(X)}$ neurons after muting. $E$, Subthreshold correlation coefficients for all cells recorded after muting (shaded region $=95 \%$ confidence interval). $\boldsymbol{F}$, Electrophysiological recording during reversible muting. Displayed are the presurgical song and two variants of the postsurgical song (tube open and tube closed). Four intracellular recordings from an $\mathrm{HVC}_{(\mathrm{RA})}$ neuron are provided. Two of these examples are from the tube closed condition (Trials \#1 and \#2). After reversible muting (opening the tube), the bird sang the song displayed below the dotted line. Two examples of song-related membrane potential in the tube open condition are given below for that neuron (Trials \#3 and \#4).

all consistency in activity of these neurons following sensory deprivation, we found minor differences in the details of songrelated electrophysiological responses (for instance, a decrease in synaptic potential amplitudes in $\mathrm{HVC}_{(\mathrm{X})}$ neurons following deafening), but the plasticity mechanisms underlying these changes are not well understood.

In this study, our nonauditory manipulations resulted in a gross disruption of singing behavior because of a disturbance of peripheral song-related processes. For instance, after a small tube was inserted into the air sac, the bird was no longer able to gen- erate sufficient pressure to produce the song (Fig. 6). Additionally, a severing of the tracheosyringeal nerve not only affects the feedback from the syrinx, but it also strongly curtails the frequencymodulated components of the song (Fig. 5). Unlike changes that accompany deafening, these nonauditory effects are often immediate (Méndez et al., 2010; Amador and Margoliash, 2013). Despite these manipulations, the synaptic patterning on HVC neurons remained relatively unaltered. These results demonstrate that any errors related to expected respiratory and syringeal patterns are not visible in the song-related activity of HVC projection neurons. This suggests that any effects of nonauditory feedback are either manifested in HVC outside of the context of singing and/or in another stage of the song production pathway. Considering all manipulations performed in this study, our data contradict the sensory model in which song-related synaptic potentials represent the perception of the ongoing motor act (Fig. 1B).

Despite the fact that sensory feedback did not appear to contribute to the synaptic dynamics observed during singing in the adult zebra finch, the possibility remains that these inputs may be playing a larger role in shaping HVC activity in other contexts. During early development, sensory feedback is crucial for the process of song learning in juvenile zebra finches (Price, 1979). This sensorimotor period is marked by significant structural changes in HVC projection neurons (Roberts et al., 2010), which have been proposed to play an important role in encoding the song of the tutor (Roberts et al., 2012). During this time, robust multiunit activity can be evoked within HVC in response to the playback of the tutor song (Nick and Konishi, 2005), but the relative impact of sensory feedback on identified HVC cell types during song learning has not been established. Once the zebra finch song has been crystallized in adulthood, the premotor circuitry appears to disengage from sensory feedback during singing, potentially so that song production can be reliably and precisely executed. It should be noted that other species capable of producing more complex songs may rely upon sensory responses within HVC (Prather et al., 2008; Sakata and Brainard, 2008) to flexibly adapt their behavior (Sakata and Brainard, 2006).

A motor source for song-related synaptic activity?

Motor commands have long been thought to require sensory feedback to produce precise skilled movements (Rothwell et al., 1982). In this study, we have demonstrated that the sequencegenerating circuitry within HVC of the zebra finch exclusively 
receives motor inputs during singing rather than on-line sensory feedback. Our observations support the notion that synaptic activity onto HVC projection neurons is instead likely to be a reflection of the ongoing motor pattern (Fig. 1C). Motor-related signals could arise from a number of sources. For instance, the nucleus interfacialis of the nidopallium (NIf) not only acts as an important source of sensory information onto HVC (Cardin and Schmidt, 2004; Coleman and Mooney, 2004; Cardin et al., 2005; Roy and Mooney, 2009), but also may play a role in motor patterning. During sleep replay events (Dave and Margoliash, 2000), NIf appears to be the primary driver of HVC bursts (Hahnloser and Fee, 2007). NIf has also been shown to exhibit activity that precedes the onset of vocalizations (McCasland, 1987; Lewandowski and Schmidt, 2011; Lewandowski et al., 2013). Another nucleus that has been proposed to be important for song-related motor patterning is the thalamic nucleus uvaeformis (Uva), which projects to HVC (Coleman et al., 2007). Bilateral lesions to Uva have been shown to eliminate singing behavior (Coleman and Vu, 2005). Previous recordings in NIf and Uva during singing revealed activity that was neither sparse nor stereotyped (McCasland, 1987; Williams and Vicario, 1993; Lewandowski and Schmidt, 2011), which is inconsistent with the synaptic patterning we measured in HVC. Since those studies relied upon multi-unit electrophysiology, further research is needed to better understand single neuron responses in these regions.

The most likely origin of premotor synaptic activity during singing is from HVC projection neurons themselves (Fig. 1C). Previous paired intracellular recordings have revealed that HV$\mathrm{C}_{(\mathrm{RA})}$ neurons form monosynaptic excitatory connections onto both $\mathrm{HVC}_{(\mathrm{X})}$ neurons as well as other $\mathrm{HVC}_{(\mathrm{RA})}$ neurons, while $\mathrm{HVC}_{(\mathrm{X})}$ neurons appear to be less frequently connected onto other HVC projection cells (Mooney and Prather, 2005). In addition, the extremely precise timing associated with $\mathrm{HVC}_{(\mathrm{RA})}$ bursts during singing matches the extraordinary reliability of the EPSPs observed. These results are consistent with the possibility that synaptic activity of $\mathrm{HVC}$ projection neurons during singing originates from the $\mathrm{HVC}_{(\mathrm{RA})}$ population.

\section{Intracellular recordings provide a window into a motor sequence-generating network}

Previously proposed models of HVC were constructed using strong excitatory inputs linking active ensembles of neurons into a purely feedforward network ( $\mathrm{Li}$ and Greenside, 2006; Jin et al., 2007). Experimentally, intracellular recordings in HVC of zebra finches (Long et al., 2010) has supported the idea that a chain of synaptically connected neurons drives the motor sequence of singing. Here, we add a new feature to this neural architecture, specifically the presence of additional connections from other HVC premotor neurons that are active at a range of different times throughout the song (Fig. $1 C$ ), forming a recursively connected excitatory circuit (Mauk and Buonomano, 2004; Mooney and Prather, 2005; Long et al., 2010; Laje and Buonomano, 2013). The mechanisms underlying precisely timed burst propagation throughout the HVC network (Hahnloser et al., 2002; Long et al., 2010) in the presence of multiple excitatory premotor inputs remain unresolved.

In the mammalian motor cortex, it has been shown that the process of motor learning is associated with a sparsening (Komiyama et al., 2010) and temporal sharpening (Masamizu et al., 2014; Peters et al., 2014) of neural activity as learned sequences emerge. In the juvenile songbird, the activity of single HVC premotor neurons has not yet been described, but the possibility exists that multiple premotor links may be useful for ex- ploring a range of potential vocal behaviors during song learning. In the adult, recursive excitatory connectivity within HVC may also enable premotor neurons to flexibly assume different roles over the span of days. Current estimates indicate that some (Amador et al., 2013) or all (Fee et al., 2004) of the time points during the song are represented by hundreds of HVC premotor neurons, suggesting a high degree of redundancy and providing an opportunity for such "background changes" (Rokni et al., 2007; Huber et al., 2012) to allow the network and the associated behavior to adapt to environmental demands (Tumer and Brainard, 2007; Ali et al., 2013).

\section{References}

Ali F, Otchy TM, Pehlevan C, Fantana AL, Burak Y, Ölveczky BP (2013) The basal ganglia is necessary for learning spectral, but not temporal, features of birdsong. Neuron 80:494-506. CrossRef Medline

Amador A, Margoliash D (2013) A mechanism for frequency modulation in songbirds shared with humans. J Neurosci 33:11136-11144. CrossRef Medline

Amador A, Perl YS, Mindlin GB, Margoliash D (2013) Elemental gesture dynamics are encoded by song premotor cortical neurons. Nature 495: 59-64. CrossRef Medline

Ashmore RC, Renk JA, Schmidt MF (2008) Bottom-up activation of the vocal motor forebrain by the respiratory brainstem. J Neurosci 28:26132623. CrossRef Medline

Bauer EE, Coleman MJ, Roberts TF, Roy A, Prather JF, Mooney R (2008) A synaptic basis for auditory-vocal integration in the songbird. J Neurosci 28:1509-1522. CrossRef Medline

Bottjer SW, Arnold AP (1984) The role of feedback from the vocal organ. I. Maintenance of stereotypical vocalizations by adult zebra finches. J Neurosci 4:2387-2396. Medline

Brainard MS, Doupe AJ (2000) Interruption of a basal ganglia-forebrain circuit prevents plasticity of learned vocalizations. Nature 404:762-766. CrossRef Medline

Cardin JA, Schmidt MF (2004) Auditory responses in multiple sensorimotor song system nuclei are co-modulated by behavioral state. J Neurophysiol 91:2148-2163. CrossRef Medline

Cardin JA, Raksin JN, Schmidt MF (2005) Sensorimotor nucleus NIf is necessary for auditory processing but not vocal motor output in the avian song system. J Neurophysiol 93:2157-2166. CrossRef Medline

Coleman MJ, Mooney R (2004) Synaptic transformations underlying highly selective auditory representations of learned birdsong. J Neurosci 24: 7251-7265. CrossRef Medline

Coleman MJ, Vu ET (2005) Recovery of impaired songs following unilateral but not bilateral lesions of nucleus uvaeformis of adult zebra finches. J Neurobiol 63:70-89. CrossRef Medline

Coleman MJ, Roy A, Wild JM, Mooney R (2007) Thalamic gating of auditory responses in telencephalic song control nuclei. J Neurosci 27:1002410036. CrossRef Medline

Dave AS, Margoliash D (2000) Song replay during sleep and computational rules for sensorimotor vocal learning. Science 290:812-816. CrossRef Medline

Fee MS, Kozhevnikov AA, Hahnloser RH (2004) Neural mechanisms of vocal sequence generation in the songbird. Ann N Y Acad Sci 1016:153-170. CrossRef Medline

Hahnloser RH, Fee MS (2007) Sleep-related spike bursts in HVC are driven by the nucleus interface of the nidopallium. J Neurophysiol 97:423-435. CrossRef Medline

Hahnloser RH, Kozhevnikov AA, Fee MS (2002) An ultra-sparse code underlies the generation of neural sequences in a songbird. Nature 419:65-70. CrossRef Medline

Hamaguchi K, Tschida KA, Yoon I, Donald BR, Mooney R (2014) Auditory synapses to song premotor neurons are gated off during vocalization in zebra finches. eLife 3:e01833. CrossRef Medline

Huber D, Gutnisky DA, Peron S, O'Connor DH, Wiegert JS, Tian L, Oertner TG, Looger LL, Svoboda K (2012) Multiple dynamic representations in the motor cortex during sensorimotor learning. Nature 484:473-478. CrossRef Medline

Jin DZ, Ramazanoğlu FM, Seung HS (2007) Intrinsic bursting enhances the robustness of a neural network model of sequence generation by avian brain area HVC. J Comput Neurosci 23:283-299. CrossRef Medline 
Komiyama T, Sato TR, O'Connor DH, Zhang YX, Huber D, Hooks BM, Gabitto M, Svoboda K (2010) Learning-related fine-scale specificity imaged in motor cortex circuits of behaving mice. Nature 464:1182-1186. CrossRef Medline

Konishi M (1965) The role of auditory feedback in the control of vocalization in the white-crowned sparrow. Z Tierpsychol 22:770-783. Medline

Kozhevnikov AA, Fee MS (2007) Singing-related activity of identified HVC neurons in the zebra finch. J Neurophysiol 97:4271-4283. CrossRef Medline

Laje R, Buonomano DV (2013) Robust timing and motor patterns by taming chaos in recurrent neural networks. Nat Neurosci 16:925-933. CrossRef Medline

Lee AK, Manns ID, Sakmann B, Brecht M (2006) Whole-cell recordings in freely moving rats. Neuron 51:399-407. CrossRef Medline

Leonardo A, Konishi M (1999) Decrystallization of adult birdsong by perturbation of auditory feedback. Nature 399:466-470. CrossRef Medline

Lewandowski BC, Schmidt M (2011) Short bouts of vocalization induce long-lasting fast gamma oscillations in a sensorimotor nucleus. J Neurosci 31:13936-13948. CrossRef Medline

Lewandowski B, Vyssotski A, Hahnloser RH, Schmidt M (2013) At the interface of the auditory and vocal motor systems: NIf and its role in vocal processing, production and learning. J Physiol Paris 107:178-192. CrossRef Medline

Lewicki MS (1996) Intracellular characterization of song-specific neurons in the zebra finch auditory forebrain. J Neurosci 16:5855-5863. Medline

Li M, Greenside H (2006) Stable propagation of a burst through a onedimensional homogeneous excitatory chain model of songbird nucleus HVC. Phys Rev E Stat Nonlin Soft Matter Phys 74:011918. CrossRef Medline

Lombardino AJ, Nottebohm F (2000) Age at deafening affects the stability of learned song in adult male zebra finches. J Neurosci 20:5054-5064. Medline

Long MA, Fee MS (2008) Using temperature to analyse temporal dynamics in the songbird motor pathway. Nature 456:189-194. CrossRef Medline

Long MA, Lee AK (2012) Intracellular recording in behaving animals. Curr Opin Neurobiol 22:34-44. CrossRef Medline

Long MA, Jin DZ, Fee MS (2010) Support for a synaptic chain model of neuronal sequence generation. Nature 468:394-399. CrossRef Medline

Margoliash D (1983) Acoustic parameters underlying the responses of song-specific neurons in the white-crowned sparrow. J Neurosci 3:10391057. Medline

Margoliash D (1997) Functional organization of forebrain pathways for song production and perception. J Neurobiol 33:671-693. CrossRef Medline

Masamizu Y, Tanaka YR, Tanaka YH, Hira R, Ohkubo F, Kitamura K, Isomura Y, Okada T, Matsuzaki M (2014) Two distinct layer-specific dynamics of cortical ensembles during learning of a motor task. Nat Neurosci 17:987-994. CrossRef Medline

Mauk MD, Buonomano DV (2004) The neural basis of temporal processing. Annu Rev Neurosci 27:307-340. CrossRef Medline

McCasland JS (1987) Neuronal control of bird song production. J Neurosci 7:23-39. Medline

McCasland JS, Konishi M (1981) Interaction between auditory and motor activities in an avian song control nucleus. Proc Natl Acad Sci U S A 78:7815-7819. CrossRef Medline

Méndez JM, Dall'asén AG, Goller F (2010) Disrupting vagal feedback affects birdsong motor control. J Exp Biol 213:4193-4204. CrossRef Medline

Mooney R (2000) Different subthreshold mechanisms underlie song selectivity in identified $\mathrm{HVc}$ neurons of the zebra finch. J Neurosci 20:54205436. Medline

Mooney R, Prather JF (2005) The HVC microcircuit: the synaptic basis for interactions between song motor and vocal plasticity pathways. J Neurosci 25:1952-1964. CrossRef Medline

Nick TA, Konishi M (2005) Neural song preference during vocal learning in the zebra finch depends on age and state. J Neurobiol 62:231-242. CrossRef Medline

Nordeen KW, Nordeen EJ (1992) Auditory-feedback is necessary for the maintenance of stereotyped song in adult zebra finches. Behav Neural Biol 57:58-66. CrossRef Medline

Nordeen KW, Nordeen EJ (2010) Deafening-induced vocal deterioration in adult songbirds is reversed by disrupting a basal ganglia-forebrain circuit. J Neurosci 30:7392-7400. CrossRef Medline

Nottebohm F, Stokes TM, Leonard CM (1976) Central control of song in the canary, Serinus canarius. J Comp Neurol 165:457-486. CrossRef Medline

Nottebohm F, Kelley DB, Paton JA (1982) Connections of vocal control nuclei in the canary telencephalon. J Comp Neurol 207:344-357. CrossRef Medline

Peters AJ, Chen SX, Komiyama T (2014) Emergence of reproducible spatiotemporal activity during motor learning. Nature 510:263-267. CrossRef Medline

Prather JF, Peters S, Nowicki S, Mooney R (2008) Precise auditory-vocal mirroring in neurons for learned vocal communication. Nature 451:305310. CrossRef Medline

Price PH (1979) Developmental determinants of structure in zebra finch song. J Comp Physiol Psych 93:260-277. CrossRef

Roberts TF, Tschida KA, Klein ME, Mooney R (2010) Rapid spine stabilization and synaptic enhancement at the onset of behavioural learning. Nature 463:948-952. CrossRef Medline

Roberts TF, Gobes SM, Murugan M, Ölveczky BP, Mooney R (2012) Motor circuits are required to encode a sensory model for imitative learning. Nat Neurosci 15:1454-1459. CrossRef Medline

Rokni U, Richardson AG, Bizzi E, Seung HS (2007) Motor learning with unstable neural representations. Neuron 54:653-666. CrossRef Medline

Rothwell JC, Traub MM, Day BL, Obeso JA, Thomas PK, Marsden CD (1982) Manual motor performance in a deafferented man. Brain 105: 515-542. CrossRef Medline

Roy A, Mooney R (2009) Song decrystallization in adult zebra finches does not require the song nucleus NIf. J Neurophysiol 102:979-991. CrossRef Medline

Sakata JT, Brainard MS (2006) Real-time contributions of auditory feedback to avian vocal motor control. J Neurosci 26:9619-9628. CrossRef Medline

Sakata JT, Brainard MS (2008) Online contributions of auditory feedback to neural activity in avian song control circuitry. J Neurosci 28:1137811390. CrossRef Medline

Scharff C, Kirn JR, Grossman M, Macklis JD, Nottebohm F (2000) Targeted neuronal death affects neuronal replacement and vocal behavior in adult songbirds. Neuron 25:481-492. CrossRef Medline

Tchernichovski O, Nottebohm F, Ho CE, Pesaran B, Mitra PP (2000) A procedure for an automated measurement of song similarity. Anim Behav 59:1167-1176. CrossRef Medline

Tumer EC, Brainard MS (2007) Performance variability enables adaptive plasticity of 'crystallized' adult birdsong. Nature 450:1240-1244. CrossRef Medline

Vicario DS (1991) Contributions of syringeal muscles to respiration and vocalization in the zebra finch. J Neurobiol 22:63-73. CrossRef Medline

Vu ET, Mazurek ME, Kuo YC (1994) Identification of a forebrain motor programming network for the learned song of zebra finches. J Neurosci 14:6924-6934. Medline

Williams H (2004) Birdsong and singing behavior. Ann N Y Acad Sci 1016: 1-30. CrossRef Medline

Williams H, McKibben JR (1992) Changes in stereotyped central motor patterns controlling vocalization are induced by peripheral nerve injury. Behav Neural Biol 57:67-78. CrossRef Medline

Williams H, Vicario DS (1993) Temporal patterning of song production: participation of nucleus uvaeformis of the thalamus. J Neurobiol 24:903912. CrossRef Medline

Williams SM, Nast A, Coleman MJ (2012) Characterization of synaptically connected nuclei in a potential sensorimotor feedback pathway in the zebra finch song system. PLoS One 7:e32178. CrossRef Medline

Woolley SC, Rajan R, Joshua M, Doupe AJ (2014) Emergence of contextdependent variability across a basal ganglia network. Neuron 82:208-223. CrossRef Medline 